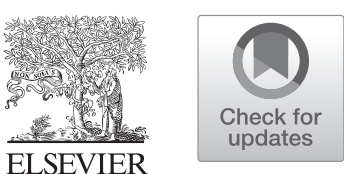

\title{
Characteristics of Liver Transplantation in Argentina: A Multicenter Study
}

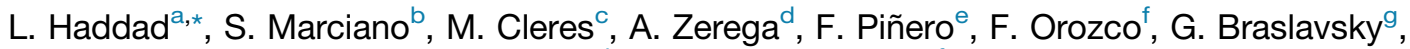

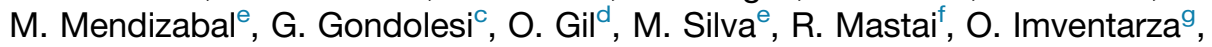 \\ V. Descalzi ${ }^{\mathrm{C}}$, and A. Gadano ${ }^{a}$

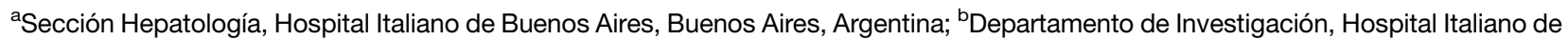 \\ Buenos Aires, Buenos Aires, Argentina; 'Unidad de hepatología y Trasplante Hepático, Hospital Universitario Fundación Favaloro, \\ Buenos Aires, Argentina; 'Unidad de Trasplante Hepático, Sanatorio Allende, Córdoba, Argentina; 'Unidad de Hígado y Trasplante \\ Hepático, Hospital Universitario Austral, Buenos Aires, Argentina; ' Unidad de Trasplante Hepático Hospital Alemán, Buenos Aires,

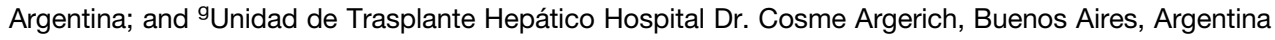

\begin{abstract}
Introduction. There is a lack of information regarding outcomes after liver transplant in Latin America.

Objectives. This study sought to describe outcomes after liver transplant in adult patients from Argentina.

Methods. We performed an ambispective cohort study of adult patients transplanted between June 2010 and October 2012 in 6 centers from Argentina. Only patients who survived after the first 48 hours postransplantation were included. Pretransplantation and posttransplantation data were collected.

Results. A total of 200 patients were included in the study. Median age at time of transplant was 50 (interquartile range [IQR] 26 to 54) years. In total, $173(86 \%)$ patients had cirrhosis, and the most frequent etiology in these patients was hepatitis $\mathrm{C}(32 \%)$. A total of $35(17 \%)$ patients were transplanted with hepatocellular carcinoma. In patients with cirrhosis, the median Model for End-Stage Liver Disease (MELD) score at time of liver transplant was 25 (IQR 19 to 30). Median time on the waiting list for elective patients was 101 (IQR 27 to 295) days, and 3 (IQR 2 to 4) days for urgent patients. Almost $40 \%$ of the patients were readmitted during the first 6 months after liver transplant. Acute rejection occurred in $27 \%$ of the patients. Biliary and vascular complications were reported in $39(19 \%)$ and $19(9 \%)$ patients, respectively. Renal failure, diabetes, and dyslipidemia were present in $40(26 \%), 87(57 \%)$, and $77(50 \%)$ at 2 years, respectively.

Conclusions. We believe the information contained in this article might be of value for reviewing current practices and developing local policies.
\end{abstract}

$\mathbf{L}^{\mathrm{r}}$ IVER transplant (LT) is a well-established therapeutic practice in Argentina for patients with end-stage liver disease. In Argentina, the first LT was performed in 1988, and during past decades the annual number of LTs has increased steadily, placing Argentina at the top of Latin American LT rates [1]. This was possible due to the advances in surgical techniques, peritransplant intensive care, and immunosuppressive regimens, which resulted in significant improvements in short-term survival.

$0041-1345 / 18$

https://doi.org/10.1016/j.transproceed.2017.11.072
This study has received funds from Novartis in the setting of a Third Party Trial.

*Address correspondence to Leila Haddad, Unidad de Trasplante Hepático, Hospital Italiano de Buenos Aires, Address Tte. Gral. J.D Perón 4190, C1199ABB, Buenos Aires, Argentina. E-mail: Leila.haddad@hospitalitaliano.org.ar

(c) 2017 Elsevier Inc. All rights reserved. 230 Park Avenue, New York, NY 10169 
Although there is continual worldwide improvement in patient survival, LT patients may experience serious complications that not only contribute to significant morbidity and mortality, but also represent an extremely high cost to the health care system. A clear example of these are postLT infections, which are estimated to occur in more than $50 \%$ of the LT recipients, being one of the most frequent complications during the early postoperative period $[2,3]$ and remaining the most common indication of hospital readmission [3]. New-onset diabetes mellitus (NODM) after LT is another well-known complication; it occurs in $2.5 \%$ to $25 \%$ [4] of LT recipients and in $40 \%$ to $60 \%$ of hepatitis C virus-infected LT recipients [5]. Chronic renal failure after LT, mainly related to calcineurin inhibitors (CNI) toxicity [6-8], continues to be a major complication, with an incidence that ranges from $20 \%$ to $80 \%$. In Argentina, studies in patients on the waiting list and post-LT survival have been published [9-11], although very limited data exist for the post-LT period. Understanding post-LT complications might be useful to develop strategies to predict and prevent them, improving the quality of care and potentially reducing overall costs. The aim of this study was to describe the characteristics and outcomes of patients after LT in Argentina.

\section{PATIENTS AND METHODS}

We performed an ambispective multicenter cohort study of patients who underwent LT from June 2010 to October 2012 in the 6 LT centers from Argentina that performed the largest numbers of LT when the study took place.

Argentina has a single national waiting list. The Instituto Nacional Central Único Coordinador de Ablación e Implante (INCUCAI) is the national institute for organ allocation, and organ procurement is exclusively run by the state, with no private procurement agencies. Since Argentina adopted the Model for End-Stage Liver Disease (MELD) system in 2005 as allocation policy, all patients were grouped into 2 categories: emergency or elective. Emergency status is considered for patients with acute liver failure and for patients with primary graft failure or those with hepatic artery thrombosis during the first postoperative week. Elective patients are stratified according to the MELD score. A specific regulation includes 3 situations for MELD upgrading, which includes familial amyloidotic polyneuropathy (16 points), hepatopulmonary syndrome (20 points), and stage II hepatocellular carcinoma (HCC) (22 points); these regulations contemplate 1 additional point in MELD scores every 3 months on the waiting list. By 2010 there were more than 20 authorized LT centers in Argentina, which has a population of 40,117,096 [12]. The centers involved in the study were the Hospital Italiano de Buenos Aires, Hospital Universitario Fundación Favaloro, Sanatorio Allende de Cordoba, Hospital Universitario Austral, Hospital Alemán and Hospital General de Agudos Dr. Cosme Argerich.

Patients included in this study were older than 18 years and were transplanted using a cadaveric donor. Exclusion criteria included prior LT, combined transplant, and death during the first 48 hours after LT. Patients were followed up from the day of LT until death, retransplantation, or the end of the 2-year follow-up period.

Each center provided detailed information for the patients included in the study. Data collection was performed using an electronic form. The information collected included: demographics (age/sex); date of enrollment on the waiting list; primary diagnosis of liver disease at listing; Child-Pugh and MELD scores at inclusion on the waitlist and at the day of transplantation; history of diabetes before LT; donor characteristics; immunosuppression received; laboratory determinations at months 1, 3, 6, 12 and 24 after LT; medical and surgical complications; all-cause hospital readmissions; and graft and patient survival. All data records were checked for missing values and inconsistencies; queries were sent to all participating institutions, and corrections were made at the datacoordinating center, namely Hospital Italiano in Buenos Aires.

The estimated glomerular filtration rate (GFR) was calculated at each time point with the Modified Diet in Renal Disease (MDRD) GFR [13]. The definition of pre-LT diabetes included a history of diabetes or use of insulin or oral hypoglycemic medications. The definition of new-onset diabetes after transplantation (NODAT) was based on International Consensus Guidelines on NODAT 2003, which recommended that the diagnosis of NODAT should be based on the American Diabetes Association (ADA) criteria for type 2 diabetes $[14,15]$. Dyslipidemia was defined using the National Cholesterol Education Program (NCEP) Adult Treatment Panel (ATP) III criteria [16]. Renal failure was defined as the presence of a GFR of $<50 \mathrm{~mL} / \mathrm{min} / 1.73 \mathrm{~m}^{2}$ using the MDRD equation. Liver allograft rejection was diagnosed by biopsy according to Banff criteria [17]. Patient management and immunosuppression regimens were determined in each center. The study was conducted according to the principles of the Declaration of Helsinki and the Guidelines for Good Clinical Practices ICH E6. The study protocol was approved by the ethics committees of the participating hospitals.

\section{STATISTICAL ANALYSIS}

Discrete variables are presented as absolute and relative frequencies (percentages). Continuous variables are shown as median and interquartile ranges (IQR: 25 th percentile and 75 th percentile). To estimate the cumulative incidence of death, we calculated the time from LT to the date of death. The cumulative incidence of death at 1 and 2 years is reported with its corresponding 95\% confidence interval (95\% CI). The STATA software (StataCorp, version 14.2) was used for data analysis.

\section{RESULTS}

Liver Transplant Centers

A total of 200 patients were enrolled in the study. The total number of transplanted patients per center was as follows: Hospital Italiano from Buenos Aires: 64 (32\%), Hospital Universitario Fundación Favaloro: 36 (18\%), Sanatorio Allende: 33 (17\%), Hospital Univeritario Austral: 32 (16\%), Hospital Alemán 25 (12\%), and Hospital Dr. Cosme Argerich 10 (5\%).

\section{Indications for Liver Transplant}

Primary diagnoses at time of listing are shown in Table 1. Overall, $173(86 \%)$ patients had cirrhosis, of which hepatitis $\mathrm{C}$ and alcohol-related liver disease were the 2 most frequent etiologies. Acute liver failure and other indications for LT were registered in $10(5 \%)$ and $17(9 \%)$ patients, 
Table 1. Characteristics of Patients on the Liver Transplant Waiting List

\begin{tabular}{|c|c|}
\hline Characteristics & $\begin{array}{l}\text { Results } \\
\mathrm{n}=200\end{array}$ \\
\hline Age at transplant (y), median and IQR & $50(26-64)$ \\
\hline Sex (male), no. (\%) & $116(58 \%)$ \\
\hline HIV positve, no. (\%) & $10(5 \%)$ \\
\hline \multicolumn{2}{|l|}{ Primary diagnosis at listing, no. (\%) } \\
\hline Cirrhosis & $173(86 \%)$ \\
\hline Hepatitis C & $56(32 \%)$ \\
\hline Alcoholic liver disease & $41(24 \%)$ \\
\hline Cryptogenic cirrhosis & $27(16 \%)$ \\
\hline Autoimmune hepatitis & $22(13 \%)$ \\
\hline Primary biliary cirrhosis & $11(6 \%)$ \\
\hline Primary sclerosing cholangitis & $6(3 \%)$ \\
\hline Nonalcoholic steatohepatitis & $5(3 \%)$ \\
\hline Secondary biliary cirrhosis & $3(2 \%)$ \\
\hline Hepatitis B & $2(1 \%)$ \\
\hline Acute liver failure & $10(5 \%)$ \\
\hline Autoimmune hepatitis & $3(30 \%)$ \\
\hline Toxic hepatitis & $2(20 \%)$ \\
\hline Hepatitis B & $2(20 \%)$ \\
\hline Indeterminate & $1(10 \%)$ \\
\hline Hepatitis A & $1(10 \%)$ \\
\hline Other & $1(10 \%)$ \\
\hline Other & $17(9 \%)$ \\
\hline Hepatocellular carcinoma, no. (\%) & $35(17 \%)$ \\
\hline \multicolumn{2}{|l|}{ ABO blood group, no. (\%) } \\
\hline O & $88(44 \%)$ \\
\hline A & $86(43 \%)$ \\
\hline $\mathrm{B}$ & $23(11 \%)$ \\
\hline$A B$ & $3(2 \%)$ \\
\hline Diabetes, no. (\%) & $36(18 \%)$ \\
\hline MELD score at listing, median and IQR ${ }^{*}$ & $17(14-23)$ \\
\hline MELD score at transplant, median and IQR & $25(19-30)$ \\
\hline Body weight, median and IQR & $75(64-84)$ \\
\hline Child-Pugh score, median and IQR & $10(9-12)$ \\
\hline Total bilirubin(mg/dL), median and IQR & $5.5(2.3-12.4)$ \\
\hline Prothrombin time (seg), median and IQR & $40(26-75)$ \\
\hline $\begin{array}{l}\text { International normalized ratio prothrombin time, } \\
\text { median and IQR }\end{array}$ & $1.9(1.4-2.7)$ \\
\hline Creatinine $(\mathrm{mg} / \mathrm{dL})$, median and IQR & $1(0.7-1.5)$ \\
\hline $\begin{array}{l}\text { Glomerular filtration rate at transplant, median } \\
\text { and IQR }\end{array}$ & $88(62-133)$ \\
\hline
\end{tabular}

respectively. Thirty-five $(17 \%)$ of the patients were transplanted with HCC, 19 (54\%) of whom had a diagnosis of hepatitis C-related cirrhosis. Of the 200 LTs performed in this period, 190 were elective and 10 were emergency candidates.

\section{Pretransplant Patient Characteristics and Time on Waiting List}

Baseline characteristics of the study population are shown in Table 1. Most of the patients were middle-aged men, with a median age of 50 (IQR 26 to 64) years. Sixty-seven (33\%) patients were between the ages of 60 and 70 years, and only
Table 2. Median (and Interquartile Range) Time on Waiting List According to the ABO Group for Elective Patients (Patients Listed as Urgent Are Excluded), $\mathbf{N}=190$

\begin{tabular}{lcc}
\hline Blood Type & Number of Patients & Days on the Waiting List \\
\hline All & 190 & $101(27-295)$ \\
O & 82 & $109(31-386)$ \\
A & 82 & $87(20-266)$ \\
B & 23 & $111(13-207)$ \\
AB & 3 & $47(29-801)$ \\
\hline
\end{tabular}

$7(4 \%)$ patients were more than 70 years old at the time of LT.

The median waiting time for the 190 elective patients was 101 (IQR 27 to 295) days. The median waiting time for the 10 emergency patients was 3 (IQR 2 to 4 ) days. Tables 2 and 3 show the median time on the waiting list according to the $\mathrm{ABO}$ group for patients with and without MELD exception for HCC, respectively.

\section{Donor Characteristics}

The median age of donors was 40 (IQR 27 to 53) years. Seventy $(35 \%)$ donors were older than 50 years. The oldest donor was 84 years old. The most common causes of death were cerebrovascular disorders and head trauma, in 98 $(49 \%)$ and $86(43 \%)$ cases, respectively. In regard to donor history of infections, Chagas-positive, anti-hepatitis B core, and hepatitis $\mathrm{C}$ virus-positive donors were reported in 11 $(5 \%), 9(4 \%)$, and $2(1 \%)$ patients, respectively.

\section{Immunosuppression}

All patients received steroid-based induction regimens. Sixty-eight $(34 \%)$ patients received induction therapy with an interleukin-2 receptor antagonist. The initial maintenance regimen during the first 72 hours after LT included steroids in all patients, calcineurin inhibitors in $100(50 \%)$ patients, and mycophenolate in $36(18 \%)$ patients. Of the 100 patients who received calcineurin inhibitors, 76 (76\%) received tacrolimus, and 24 (24\%) received cyclosporine. None of the patients received mammalian target of rapamycin (mTOR) inhibitors during the first 72 hours after LT.

Of the 153 patients who completed the 2-year follow up, $62(40 \%)$ were receiving steroids, $133(87 \%)$ calcineurin inhibitors (79\% tacrolimus, $21 \%$ cyclosporine), and 86 $(56 \%)$ mycophenolate. A total of $23(15 \%)$ patients were receiving mTOR inhibitors, of whom $16(70 \%)$ received

Table 3. Median (and Interquartile Range) Time on the Waiting List for Patients With Hepatocellular Carcinoma and Supplementary Points Subdivided According to ABO Group, $\mathbf{N}=35$

\begin{tabular}{lcc}
\hline Blood Type & Number of Patients & Days on the Waiting List \\
\hline All & 35 & $117(35-195)$ \\
O & 14 & $164(35-201)$ \\
A & 17 & $76(36-118)$ \\
B & 4 & $162(61-2230)$ \\
\hline
\end{tabular}




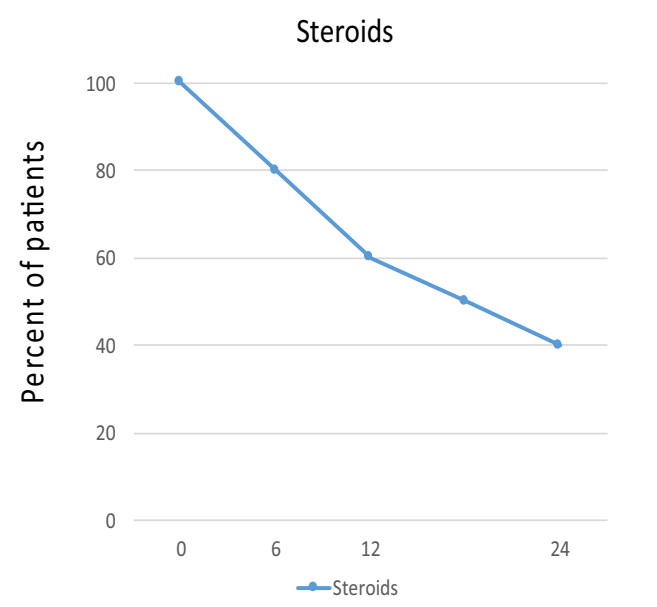

$$
\begin{aligned}
& \text { —Tacrolimus and cyclosporine } \\
& \text {-Tacrolimus } \\
& \text {-Cyclosporine }
\end{aligned}
$$

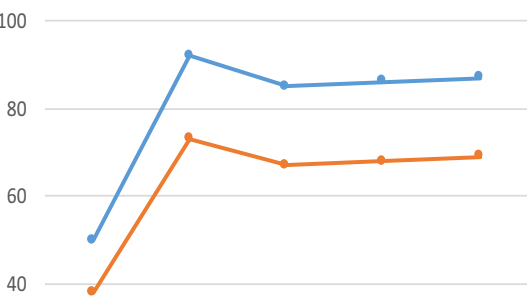

20
Fig 1. Proportion of patients receiving steroids and calcineurine inhibitors since transplant during the study period. $0=$ Liver transplant day, $\mathrm{n}=200$; at 6 months, $\mathrm{n}=184$; at 12 months, $\mathrm{n}=179$; at 24 months, $\mathrm{n}=153$. sirolimus and $7(30 \%)$ received everolimus (Figs 1 and 2). The main reasons for prescription of mTOR inhibitors (either with or without CNI inhibitors) were renal failure in $13(57 \%)$ patients, preoperative HCC in $4(17 \%)$ patients (CNI), neurotoxicity in $3(14 \%)$ patients, HCC recurrence in $2(9 \%)$ patients, and refractory acute rejection in $1(3 \%)$ patient.

\section{Patient Outcomes and Posttransplant Complications}

Of the 200 patients, 153 were alive after 2 years, 12 were retransplanted, 28 died, and 7 were lost to follow up. The overall survival rates of patients who survive past the first 48 hours after LT were $91 \%$ (95\% CI $86 \%$ to $94 \%$ ) and $85 \%$ (95\% CI 79 to $89 \%$ ) at 1 and 2 years, respectively. The causes of death are shown in Table 4. Of the $12(6 \%)$ patients who underwent retransplantation, the median time between the primary transplantation and retransplantation was 110 (IQR 11 to 361) days. The main indication of retransplantation was hepatic artery thrombosis in 4 (34\%) patients, followed by chronic rejection in $3(25 \%)$ patients, biliary complications in $3(25 \%)$ patients, primary nonfunction in $1(8 \%)$ patient, and hepatitis $\mathrm{C}$ virus recurrence in $1(8 \%)$ patient.

\section{Other Complications}

During the first 6 months of LT, 54 (27\%) patients experienced 62 episodes of acute rejection. The severity of the acute rejection episodes was as follows: 15 (24\%) mild, 22
Mycophenolate

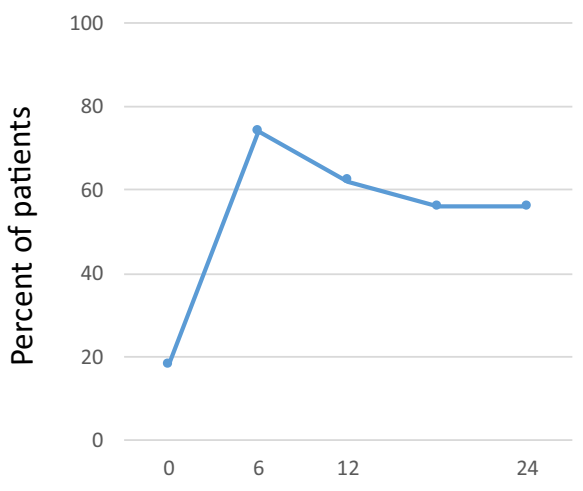

$\mathrm{mTOR}^{1}$ inhibitors

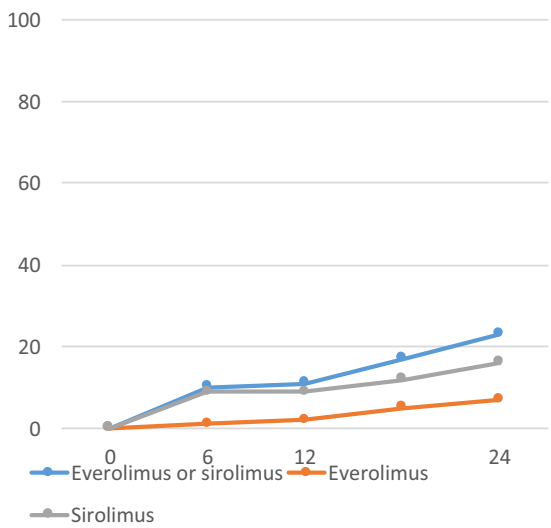

Fig 2. Proportion of patients receiving mycophenolate and mammalian target of rapamycin (mTOR) inhibitors since transplant during the study period. $0=$ Liver transplant day, $\mathrm{n}=200$; at 6 months, $\mathrm{n}=184$; at 12 months, $\mathrm{n}=179$; at 24 months, $\mathrm{n}=153$. 
Table 4. Causes of Death After Liver Transplant

\begin{tabular}{lc}
\hline \multicolumn{1}{c}{ Cause of Death } & Patients \\
Gastrointestinal bleeding & $1(4 \%)$ \\
Primary nonfunction & $2(7 \%)$ \\
Infection & $14(50 \%)$ \\
$\quad$ Bacterial infection & $12(43 \%)$ \\
Fungal infection & $1(4 \%)$ \\
Other & $1(4 \%)$ \\
Recurrence of hepatocellular carcinoma & $1(4 \%)$ \\
Recurrence of hepatitis C virus & $2(7 \%)$ \\
De novo tumor* & $2(7 \%)$ \\
Chronic rejection & $1(4 \%)$ \\
Others causes & $5(17 \%)$ \\
Cardiovascular & $2(7 \%)$ \\
Cerebrovascular & $3(11 \%)$ \\
\hline$*$ *on lung and one colorectal cancer.
\end{tabular}

$(35 \%)$ moderate, $16(26 \%)$ severe; no data were available for $9(15 \%)$ of the episodes. A total of 194 infections in 130 $(65 \%)$ patients were documented during the study period. There were $117(60 \%)$ bacterial infections, of which 49 (42\%) occurred during the first month. Viral infections were registered in $55(28 \%)$ patients; cytomegalovirus (CMV) infections were reported in $36(65 \%)$ of them. Fungal infections were documented in $15(8 \%)$ patients; 14 (93\%) of them reported as Candida species and 1 case as cryptococcal disseminated infection. Chagas transmission was documented in $3(27 \%)$ of the 11 patients who received organs from Trypanosoma cruzi-infected donors. All were treated with benznidazole.

Of the 153 patients who were alive 2 years after LT, 87 $(57 \%)$ were diabetic $(55[63 \%]$ of them with diagnosis of NODM). Seventy-seven (50\%) patients were dyslipidemic. The median creatinine at 2 years of LT was $1.18 \mathrm{mg} / \mathrm{dL}$ (IQR 0.9 to 1.4 ), and median GFR was 61.5 (IQR 48 to 80 ) $\mathrm{mL} / \mathrm{min}$. Forty $(26 \%)$ patients had a GFR lower than 50 $\mathrm{mL} / \mathrm{min}$; only 3 of them were under everolimus, and 7 under sirolimus. Of the 35 patients transplanted with HCC, 7 (20\%) developed HCC recurrence within 2 years of LT. Vascular and biliary complications and readmission are shown in Table 5 and Fig 3, respectively.

\section{DISCUSSION}

Seventeen percent of LTs are currently being performed in Latin America, and the top LT rates were found in Argentina, with 10.4 LT per million people per year [1]. Despite the comparable outcomes to those in Europe and North America [9], there is still a lack of data from our region.

As expected, cirrhosis continues to represent the main indication of LT, with a large predominance of hepatitis $\mathrm{C}$-related cirrhosis within this group of patients. It is noteworthy that autoimmune cirrhosis continues to be a leading cause of LT in Argentina [18,19]. We found that autoimmune hepatitis (AIH) was the main etiology in
Table 5. Posttransplant Vascular and Biliary Complications

\begin{tabular}{lr}
\hline \multicolumn{1}{c}{ Complication } & Total \\
$\mathrm{N}=200$ \\
\hline Vascular complication \\
Thromboses of the hepatic artery & $19(9 \%)$ \\
Early & $12(63 \%)$ \\
Late & $6(50 \%)$ \\
Thromboses of the portal vein & $6(50 \%)$ \\
Early & $7(37 \%)$ \\
Late & $3(40 \%)$ \\
Biliary complication & $4(60 \%)$ \\
Biliary anastomotic stricture & $39(19 \%)$ \\
Ischemic-type biliary lesion & $26(67 \%)$ \\
Bile leak & $7(18 \%)$ \\
\hline
\end{tabular}

*Vascular complications were classified as early (occurring during the first 30 days after liver transplant) or late (occurring more than 30 days after liver transplant).

urgent LT, in contrast to the situation in Europe and North America, where AIH is considered a relatively rare disease and represents an infrequent indication for LT, accounting for only $4 \%$ to $5 \%$ of $\mathrm{LT}$ procedures $[20,21]$.

In the pre-MELD era, patients with blood group $\mathrm{O}$ had longer waiting times for LT than patients with other blood groups $[22,23]$. Although our study was not powered to analyze this issue, a clinically significant shorter waiting time for LT was observed for patients with blood type A than for patients with other blood types.

We found that $35 \%$ of our donors were past the age of 50 years; this is also similar to reports from the United States [24]. Contradictory results have been obtained from different studies, according to which the donor age is an independent risk factor on the LT outcomes [25-28]. In our region, the use of older donors is crucial because of donor shortage.

In our study, we found that almost $40 \%$ of the patients were readmitted during the first 6 months of LT; infectious complications were frequent, affecting $65 \%$ of the patients, and were caused predominantly by bacterial origin. This is similar to what has been previously reported $[29,30]$.

In our region, extended screening for endemic infections is mandatory. It is known that the transmission rate from Trypanosoma cruzi seropositive donors to seronegative LT recipients is approximately $20 \%$ [31]. In our study, we found that $5 \%$ of the donors were positive for Trypanosoma cruzi, and had similar transmission rates to seronegative recipients.

Some regional public health problems, such as Chagas disease, tuberculosis, and some regional parasitoses, deserve special consideration during the pretransplantation assessment to implement adequate treatment or posttransplant prophylaxis. Biliary tract complications occurred in $19 \%$ of the patients, which is consistent with worldwide reports [32-34]. Anastomotic biliary strictures followed by ischemic lesions were the most frequent complications. Vascular complications occurred in $9 \%$ of the patients and mostly consisted of hepatic artery thrombosis, which was observed 


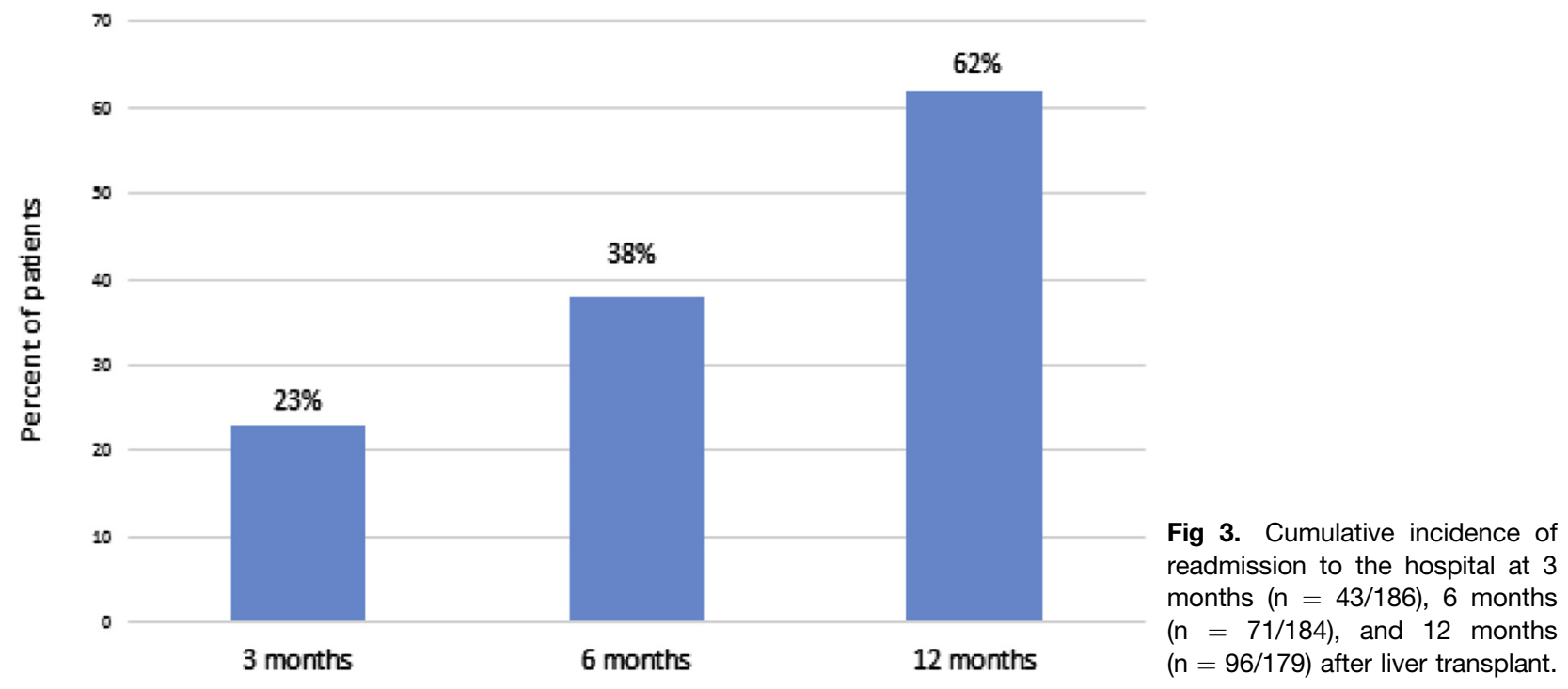

in $6 \%$ of the patients and is consistent with prior reports [35]. Acute cellular rejection episodes were observed in $27 \%$ of the patients, which is lower than previously reported [36], and could be explained by the fact that protocol biopsies were not performed in all centers.

Regarding long-term complications, it was striking to find that $57 \%$ of the patients had diabetes and most of them had NODM at 2 years after LT. Immunosuppressive drugs, and moreover steroids, have a known diabetogenic effect and are a major contributor to the development of NODM. It is important to manage NODM with therapeutic and preventive steps such as individual use of the immunosuppressive regimen with corticosteroid tapering or discontinuation, as early as possible. We found that 2 years after LT, $40 \%$ of recipients were still receiving steroids, a situation that must be reversed because of the knowledge gained from already-published data showing a negative impact of NODM on patient and graft survival after LT $[14,37]$.

It is known that mortality is higher in LT recipients with posttransplant renal failure than in patients with preserved renal function $[6,38,39]$. Two years after LT, 1 in every 4 patients in our study had a GFR lower than $50 \mathrm{~mL} / \mathrm{min}$. This situation underestimates the real burden of post-LT renal failure because patients who died or were retransplanted before that time were not taken into account. Although current guidelines suggest that CNI reduction or CNI-free protocols might overcome this issue [40,41] in our study, 2 years after LT, only 10 (25\%) patients with GFR lower than $50 \mathrm{~mL} / \mathrm{min}$ were previously switched to $\mathrm{mTOR}$ inhibitors, or used a combination of low-dose CNI and mTOR inhibitors.

Finally, we found LT survival rates of $91 \%$ and $85 \%$ at 1 and 2 years, respectively. It should be noted that patients who died during the first 2 days of LT were excluded from this analysis. This is a limitation of our study, which was mainly designed to study post-LT long-term outcomes. In conclusion, we believe that the information contained in this article might be of value to review current practices and develop local policies.

\section{REFERENCES}

[1] Salvalaggio PR, Caicedo JC, de Albuquerque LC, Contreras A, Garcia VD, Felga GE, et al. Liver transplantation in Latin America: the state-of-the-art and future trends. Transplantation 2014;98:241-6.

[2] Mueller AR, Platz KP, Kremer B. Early postoperative complications following liver transplantation. Best Pract Res Clin Gastroenterol 2004;18:881-900.

[3] Yataco M, Cowell A, David W, Keaveny AP, Taner CB, Patel T. Predictors and impact of hospital readmission following liver transplantation. Ann Hepatol 2016;15:356-62.

[4] Pageaux GP, Faure S, Bouyabrine H, Bismuth M, Assenat E. Long-term outcomes of liver transplantation: diabetes mellitus. Liver Transpl 2009;15:S79-82.

[5] Knobler H, Stagnaro-Green A, Wallenstein S, Schwartz M, Roman SH. Higher incidence of diabetes in liver transplant recipients with hepatitis C. J Clin Gastroenterol 1998;26:30-3.

[6] Ojo AO, Held PJ, Port FK, et al. Chronic renal failure after transplantation of a nonrenal organ. N Engl J Med 2003;349: 931-40.

[7] Gonwa TA, Mai ML, Melton LB, et al. End-stage renal disease (ESRD) after orthotopic liver transplantation (oltx) using calcineurin-based immunotherapy: risk of development and treatment. Transplantation 2001;72:1934-9.

[8] McCauley J, Van Thiel DH, Starzl TE, et al. Acute and chronic renal failure in liver transplantation. Nephron 1990;55: $121-8$.

[9] Cejas NG, Villamil FG, Lendoire JC, Tagliafichi V, López A, Krogh DH, et al. Improved waiting-list outcomes in Argentina after the adoption of a model for end-stage liver disease-based liver allocation policy. Liver Transpl 2013;19:711-20.

[10] McCormack L, Gadano A, Lendoire J, Imventarza O, Andriani O, Gil O, et al. Model for End-Stage Liver Disease-based allocation system for liver transplantation in Argentina: does it work outside the United States? HPB (Oxford) 2010;12:456-64.

[11] Ruf AE, Kremers WK, Chavez LL, Descalzi VI, Podesta LG, Villamil FG. Addition of serum sodium into the 
MELD score predicts waiting list mortality better than MELD alone. Liver Transpl 2005;11:336-43.

[12] Elaboración propia en base a datos del INDEC. Censo Nacional de Población, Hogares y Viviendas 2010, procesado con Redatam. Cartografía disponible en, http://www.indec.gov.ar/ codegeo.asp.

[13] Levey AS, Stevens LA, Schmid CH, et al. A new equation to estimate glomerular filtration rate. Ann Intern Med 2009;150: 604-12.

[14] Davidson J, Wilkinson A, Dantal J, et al., International Expert Panel: New-onset diabetes after transplantation: 2003 international consensus guidelines. Proceedings of an international expert panel meeting. Barcelona, Spain, 19 February 2003. Transplantation 2003;75(10 Suppl.):SS3-24.

[15] Expert Committee on the Diagnosis and Classification of Diabetes Mellitus. Report of the expert committee on the diagnosis and classification of diabetes mellitus. Diabetes Care 2003;26(Suppl. 1):S5-20.

[16] Expert Panel on Detection, Evaluation, and Treatment of High Blood Cholesterol in Adults. Executive Summary of the Third Report of the National Cholesterol Education Program (NCEP) Expert Panel on Detection, Evaluation, and Treatment of High Blood Cholesterol in Adults (Adult Treatment panel III). JAMA 2001;285:2486-97.

[17] Demetris AJ. International Panel. Banff schema for grading liver allograft rejection: an international consensus document. Hepatology 1997;25:658-63.

[18] Mendizabal M, Marciano S, Videla G, Anders M, Zerega A, et al. Changing etiologies and outcomes of acute liver failure: perspectives from 6 transplant centers in Argentina. Liver Transpl 2014;20:483-9.

[19] Klein FR, Klin PA. Status and perspectives of liver transplantation in Argentina. Int Anesthesiol Clin 2006;44:99-109.

[20] Adam R, Karam V, Delvart V, et al. Evolution of indications and results of liver transplantation in Europe. A report from the European Liver Transplant Registry (ELTR). J Hepatol 2012;57:675-88.

[21] Seaberg EC, Belle SH, Beringer KC, Schivins JL, Detre KM. Liver transplantation in the United States from 19871998: updated results from the Pitt-UNOS Liver Transplant Registry. Clin Transpl 1998:17-37.

[22] Miranda B, Cañón J, Cuende N, Garrido G, Naya MT, Fernández-Zincke E. Disparities in access to liver transplantation in Spain. Transplantation 2003;76:1398-403.

[23] Fink MA, Berry SR, Gow PJ, Angus PW, Wang BZ, Muralidharan V, et al. Risk factors for liver transplantation waiting list mortality. J Gastroenterol Hepatol 2007;22:119-24.

[24] Lué A, Solanas E, Baptista P, et al. How important is donor age in liver transplantation? World J Gastroenterol 2016;22: 4966-76.

[25] Emre S, Schwartz ME, Altaca G, Sethi P, Fiel MI, Guy SR, et al. Safe use of hepatic allografts from donors older than 70 years. Transplantation 1996;62:62-5.

[26] Rodríguez González F, Jiménez Romero C, Rodríguez Romano D, Loinaz Segurola C, Marqués Medina E, Pérez
Saborido B, et al. Orthotopic liver transplantation with 100 hepatic allografts from donors over 60 years old. Transplant Proc 2002;34: 233-4.

[27] Adam R, Cailliez V, Majno P, Karam V, McMaster P, Caine RY, et al. Normalised intrinsic mortality risk in liver transplantation: European Liver Transplant Registry study. Lancet 2000;356:621-7.

[28] Burroughs AK, Sabin CA, Rolles K, Delvart V, Karam V, Buckels J, et al. 3-month and 12-month mortality after first liver transplant in adults in Europe: predictive models for outcome. Lancet 2006;367:225-32.

[29] Fishman JA. Infection in solid-organ transplant recipients. N Engl J Med 2007;357:2601-14.

[30] Kim SI. Bacterial infection after liver transplantation. World J Gastroenterol 2014;20:6211-20.

[31] Huprikar S, Bosserman E, Patel G, et al. Donor-derived Trypanosoma cruzi infection in solid organ recipients in the United States, 2001-2011. Am J Transplant 2013;13:2418-25.

[32] Greif F, Bronsther OL, Van Thiel DH, Casavilla A, Iwatsuki S, Tzakis A, et al. The incidence, timing, and management of biliary tract complications after orthotopic liver transplantation. Ann Surg 1994;219:40-5.

[33] Sundaram V, Jones DT, Shah NH, et al. Posttransplant biliary complications in the pre- and post-model for end-stage liver disease era. Liver Transpl 2011;17:428-35.

[34] Seehofera D, Euricha D, Veltzke-Schliekera W, Neuhausa P. Biliary complications after liver transplantation: old problems and new challenges. Am J Transplant 2013;13: 253-65.

[35] Duffy JP, Hong JC, Farmer D, Ghobrial R, Yersiz H, Hiatt J, et al. Vascular complications of orthotopic liver transplantation: experience in more than 4,200 patients. J Am Coll Surg 2009;208:896-903.

[36] Pfitzmann P, Nussler N, Hippler-Benscheidt M, Neuhaus R, Neuhaus P. Long-term results after liver transplantation. Transpl Int 2008;21:234-46.

[37] Baid S, Cosimi AB, Farrell ML, Schoenfeld DA, Feng S, Chung RT, et al. Posttransplant diabetes mellitus in liver transplant recipients: risk factors, temporal relationship with hepatitis $\mathrm{C}$ virus allograft hepatitis, and impact on mortality. Transplantation 2001;72:1066-72.

[38] Sirivatanauksorn Y, Parakonthun T, Premasathian N, et al. Renal dysfunction after orthotopic liver transplantation. Transplant Proc 2014;46:818-21.

[39] Watt KD, Pedersen RA, Kremers WK, et al. Evolution of causes and risk factors for mortality post-liver transplant: results of the NIDDK long-term follow-up study. Am J Transplant 2010;10: $1420-7$.

[40] Londono MC, Rimola A, O'Grady J, Sanchez-Fueyo A. Immunosuppression minimization vs. complete drug withdrawal in liver transplantation. J Hepatol 2013;59:872-9.

[41] Beckebaum S, Cicinnati VR, Radtke A, Kabar I. Calcineurin inhibitors in liver transplantation-still champions or threatened by serious competitors? Liver Int 2013;33: 656-65. 